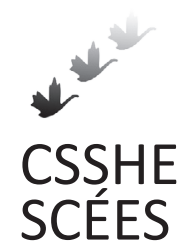

Canadian Journal of Higher Education Revue canadienne d'enseignement supérieur

Volume 45, No. 4, 2015, pages $283-297$

\title{
New Faculty Experience in Times of Institutional Change
}

\author{
Michelle Yeo, Deb Bennett, Jane Stoneman McNichol, \& Cari Merkley \\ Mount Royal University
}

\begin{abstract}
Many post-secondary institutions in Canada over the past decade have made the transition from college to university status. The researchers on this team were hired in the midst of such a transition at one western Canadian institution. As new faculty we were navigating the normal tides of adjusting to a new faculty position, but our induction occurred in a shifting institutional context. Our research question, "What is the new faculty experience in a transitional institution?" guided a five-year focused ethnography, beginning as a selfstudy of the research team and expanding into 60 interviews with 31 participants over several years. The results demonstrate that a more complex theory is required to reflect the experience of new faculty than has appeared previously in the literature. We propose a framework of competing discourses.
\end{abstract}

\section{Résumé}

$\mathrm{Au}$ cours de la dernière décennie, plusieurs établissements d'enseignement postsecondaire du Canada ont obtenu un statut universitaire. L'un d'entre eux, établi dans l'Ouest canadien, a même recruté l'équipe de chercheurs du présent article pendant sa transition. En effet, bien que l'établissement se soit adapté à la mouvance engendrée par ce processus, l'investiture de l'équipe a eu lieu dans un contexte de mutation au sein des établissements d'enseignement. La question à l'origine de l'étude, « Comment un établissement d'enseignement postsecondaire vit-il l'acquisition d'un nouveau statut universitaire? ", a orienté des travaux ethnographiques d'une durée de cinq ans, qui ont d'abord pris la forme d'une auto-analyse de l'équipe des chercheurs pour ensuite prendre la forme 60 entrevues avec 31 participants, échelonnées sur plusieurs années. Les résultats montrent qu'une théorie plus complexe que celle élaborée dans les écrits précédents est nécessaire pour traduire l'expérience vécue par les établissements nouvellement investis du statut universitaire. Nous proposons ici un cadre des interprétations contradictoires. 
In recent years, many post-secondary institutions across Canada have transitioned from colleges to universities. Founded over 100 years ago, our western Canadian institution had long operated as a community college, with two-year university transfer and applied degree programs. The transition to an undergraduate university culminated in the fall of 2009, when the institution officially changed its name in a ceremony presided over by the provincial premier.

The ceremony came after years of preparation, including the hiring of large numbers of new faculty in the years leading up to the change. We four researchers were hired in the same 2007 cohort, which to that date was the largest cohort of new faculty- but then it was exceeded in each of the following two years. We are a mid-sized educational institution, with roughly 400 full-time faculty and 12,000 students. More than half of the current full-time faculty members were hired since 2007.

As new faculty, we immediately became aware of the momentous shift happening around us. We were navigating the normal tides of adjusting to a new position, for all of us our first tenure-track faculty position at any institution, but were aware that this induction was occurring in a rapidly shifting context. (At Mount Royal University the concept of tenure refers to a permanent appointment and represents a major commitment between the institution and the employee. Tenure recommendations and decisions are made on the basis of meeting established standards during the probationary period and evidence of the clear promise of continuing intellectual and professional development.) We wondered, "What is the new faculty experience in a transitional institution?" This research question guided what became a five-year project, beginning as a self-study of the research team and expanding into 60 interviews with 31 participants over several years. Although much work has been done on the induction of new faculty into post-secondary institutions, it is our contention that in the context of a large transition, such as that from college to university, a more complex theory is required to reflect the experience of new faculty than has appeared previously in the literature.

\section{Theoretical Framework and Literature Review}

The extensive literature that exists on the experience of new faculty presents a picture of significant challenges that faculty face when embarking on their new role (Boice, 1991; Eddy \& Gaston-Gayles, 2008; Menges, 1999b). While post-secondary institutions vary across countries in their organizational structures and funding models, many of the dynamics reported in the literature seem to transcend national boundaries. Murray (2008) contends that "even a cursory review of the literature reveals adjustment to academic life is often stressful and demoralizing" (p. 108). Common concerns of faculty are struggles with the shortage of time in which to accomplish everything, uncertainty regarding exactly what is expected of them, and challenges in balancing professional and personal responsibilities (Austin, 2003; Boice, 1991, 2000; Menges, 1999b; Rice, Sorcinelli, \& Austin, 2000; Sorcinelli, 1994, 2000, 2002). In a landmark study of American academics (1999a), Menges identified the themes in new faculty life as stress, time, socialization, and evaluation. New faculty members experience significant stress in adjusting to the demands of their new positions. Many report they spend inordinate amounts of time preparing for their classes yet still often do not feel prepared, leaving little time to pursue expected research agendas (Murray, 2008, p. 111; Solem \& Foote, 2006, p. 212). Despite 
the pervasive difficulty of getting everything done, faculty often blame themselves. Murray (2008) found that faculty, "frustrated over their inability to find sufficient time for scholarship, lamented their poor time management skills" (p. 110). Depending upon the supports provided by the institution, and factors such as the effectiveness of their chair (Solem \& Foote, 2006, p. 192), new faculty may feel a sense of isolation in their new role (Sorcinelli, 1994), often in contrast to their experiences as graduate students or working in professions (Menges, 1999a). The importance of supportive relationships with colleagues is emphasized throughout the literature (Boice, 1991), but significant to this study is the importance found by Murray (2008) of having colleagues at a similar point of career development.

More recent work on the experiences of new faculty (also termed early-career academics in the literature) seeks to emphasize the specific role the institutional mission plays in the development of academic identity. Gale (2011) writes that previous work on new faculty academic identity "generally assumed that higher education was a homogenous sector, modeled on older, research-orientated universities and did not suggest that the specific institutional context played a major part in framing this role" (p. 216). For example, Gale found that the patterns of socialization previously outlined in the literature did not resonate with the experiences of faculty recently hired at a teaching-focused UK institution, as the greater influence in the first few years for these academics was their teaching and contact with students, rather than relationships with their disciplinary peers.

In this context, literature related to transitioning institutions is relevant. Studies and papers about the transition from college to university in the Canadian context typically focus on organizational change rather than on the experience of new faculty (e.g., Dennison, 2006; Levin, 2003; MacQuarrie, Kondra, \& Lamertz, 2013; Marshall, 2008). Faculty experiences with such change have been investigated in other higher education contexts, although the differing historical, economic, and political drivers behind such institutional transformations should be noted. For example, one South African study considered transitional issues for teacher educators and new expectations for scholarship at their institution; Chetty and Lubben (2008) observe that, particularly for mid-career faculty, "the institution in which they work at the present moment is very different from the institution they joined a decade ago" (p. 819). Work on faculty behaviour at "striving" institutionsthose seeking to raise their standing in university rankings through, in part, enhanced research output-may also be relevant in the context of our transition to a university, as expectations for research and scholarship were explicitly raised in the process (e.g., Gonzales, 2012, 2014; O’Meare \& Bloomgarden, 2011).

While there is little in the literature focusing specifically on new faculty experience in the context of such change, some interesting arguments relative to new faculty experience emerge. Perry, Menec, and Struthers (1999) make claims about the importance of independence and autonomy for new faculty, defined as "the ability to structure and influence assigned responsibilities in teaching, research, and service" (p. 187), and control, defined from the psychological literature as "a person's perceived capacity to influence and predict events in his or her life" (p. 187). They cite Boice's (1991) contention that "negative experiences early in the careers of new hires can have disastrous, long-lasting consequences" (Perry, Menec, \& Struthers, 1999). This is significant in the context of a transitional institution, because of a general feeling of uncertainty and lack of clarity surrounding the 
future as new structures and processes are created on the fly. In addition, this particular study reveals a fascinating and counterintuitive phenomenon: the satisfaction and perceived control of faculty in single-mission (either teaching colleges or research universities) versus what they call dual-mission institutions (such as undergraduate liberal arts institutions). Their findings suggest that "institutions with more focused missions may put less pressure on faculty" and that adjustment is most difficult in dual-mission institutions (p. 202). In our case, the institution has undergone a transition from a single mission to a dual mission or, according to Perry, Menec, and Struthers, from a context presenting the easiest adjustment scenario (the teaching college) to the most difficult (the undergraduate university).

Most of the literature on new faculty simply lists the themes found in interviewing new faculty and suggests potential supports and implications for administrators. A few researchers pursue a more complex approach, such as Trowler and Knight (2000) and, more recently, Roxa and Martensson (2009). Roxa and Martensson take a socio-cultural view in understanding new faculty, particularly in relation to their approach to teaching and learning, focusing on collegial conversations. They argue that faculty develop their personal understanding of teaching and learning in the context of social life in the academy. They find that faculty mainly have these significant conversations with a very small number of people, usually within their discipline but not necessarily within the organizational boundaries of a department. They argue that these conversations shape "personal theories" of teaching and learning more than the pedagogic theory or literature, and that they play a central role in the life of faculty and the shaping of identities.

Finally, the work of Trowler and Knight (2000) is significant to our study. In their analysis of interviews with new faculty from 10 Canadian and English universities, they make use of two theoretical frameworks in combination: Engestrom's activity system theory $(1987,1990)$ and Lave and Wenger's well known work on communities of practice (1991). Trowler and Knight argue:

If we are to understand how [new faculty] "come to know" about the rules of their new workplaces, we need to treat localized activity systems or communities of practice as important sites in the acquisition, enactment and creation of culture and knowledgeability, and to reflect upon the processes involved in identity-construction. (p. 28)

The central argument of Trowler and Knight is that the localized community of teams and departments is much more important than the larger institution. Trowler and Knight declare that the behavioural and discursive practices of a community are what the new faculty member must "come to know," and that these discourses are often very difficult to learn because of the limits of intersubjectivity, defined as the practice of members of a system sharing some aspects of their situational definitions (p. 31). They point out that multiple layers of intersubjectivity may exist, and that "the constructs formed by members of activity systems are ... also provisional and influenced by power relations" (p. 32). The complexity of Trowler and Knight's theoretical position was reflected in the complex themes of our own data, which we have conceived as a series of discourses in tension rather than the unified picture of thematic stressors presented by the majority of the literature. Our study began by using the framework established by Menges (1999a) to structure 
our initial thinking and interviewing about new faculty. We intended to find out whether these factors held constant in the context of large-scale institutional change. However, our data suggest a more complex set of dynamics in the context of institutional transformation, not only in the experience of new faculty but also in the role they actively play in shaping the system they are simultaneously assimilating into. Trowler and Knight argue, "We need fine-grained ethnographic studies at the local level to illuminate and exemplify the important social processes at work within communities of practice in higher education settings" (p. 40). It is this kind of study that our current project represents.

\section{Methodology}

\section{Research Design}

The interpretive approach taken in this research study is best described as a focused ethnography, because of the "intimate knowledge of the fields to be studied" (Knoblauch, 2005, p. 2) held by the researchers; "it focuses on small elements of one's own society" (p. 5). Focused ethnographies are defined by Muecke (1994) as "time limited exploratory studies within a fairly discrete community or organization" (p. 199). This approach is often useful in health care and academic settings. Characteristics of a focused ethnography relevant to our study are as follows: it is problem focused and context specific; it involves a limited number of participants; there is episodic participant observation; and participants usually hold "a store of knowledge and experience relative to the problem or phenomenon of study” (p. 199).

Additional features of a focused ethnography include electronic recording of the data as well as the intensive and collaborative approach to the data analysis by the team. Knoblauch (2005) describes what he terms "data sessions" where "interpretations and analyses can be made intersubjectively accessible to a degree unbeknownst in common text procedures" (p. 7). These kinds of sessions were core to our theorizing process.

\section{Participants and Data Collection}

The data were collected over three academic years (2007-2008, 2008-2009, 20092010). The research team spent the first year in a self-study process (Cohort 1), where group discussions were recorded and journal entries were written by team members on themes previously highlighted in the literature. The original team consisted of seven members, some of whom have since left the institution. Semistructured interviews were recorded with all seven in the spring of their second year, and final interviews were conducted with four members in the spring of their third year. During the second year of the study (2008-2009), nine participants were recruited from the next cohort of new faculty (Cohort 2) and were interviewed in the fall. All participants beyond the research team were recruited at their new faculty orientations; research team members made a brief presentation and offered an opportunity to sign up, as approved by our Research Ethics Board. All participants who indicated an interest were included in the study. Follow-up interviews were conducted in the spring with eight of these participants, and a final interview was recorded at the end of their second year with six. During the third year of data collection (2009-2010), 15 new faculty were recruited (Cohort 3), and these participants were interviewed in the fall of their first year; 11 were interviewed again in the spring. 
All in all, there were 31 participants, who were interviewed one to three times over three years, for a total of 60 interviews recorded; additionally, the group recordings were made and the journal entries collected. Of the 31 participants, 26 were female, five were male; they came from all faculties at the institution. All interviews were audio-recorded and transcribed; they were coded by pairs of researchers working together and then discussed by the whole team, with the exception of the first set of interviews, which were coded by all members of the research team independently. Multiple data sessions were held to compare and discuss interpretations of the data, resulting in an early version of the competing discourses described below. This structure was refined as additional interviews were analyzed, and we agree with Knoblauch (2005) in his speculation that "data sessions constitute one of the most important features of focused ethnographies" (p. 10). Finally, all data were entered into the qualitative data software NVivo to enable management of the data set and to help confirm findings.

\section{Discourses in Tension}

There were no universal or unequivocal experiences, but similar tensions were evident for all the participants in their work (Table 1). First, new faculty expressed tension around a dynamic of shaping and being shaped, which was felt as a kind of power dynamic between the self and the institution. Participants were aware that they needed to adapt to the institution, but at the same time, the institution was carving out a new identity, and thus they frequently expressed an awareness of actively contributing to shaping that institution. Second, there was a sense that the institution and the new faculty were navigating change without a road map. Participants expressed in different ways that change was happening quickly and the future was unknown. Finally, an important aspect of the interviews focused on evolving identities-both of the new faculty and of the institution itself. The following is an exploration of the discourses we found within each of these broad areas. The quotes from participant interviews are identified by cohort (Cohort 1 was hired in 2007, Cohort 2 in 2008, and Cohort 3 in 2009); by which year of their time at the institution they were in at the time of the interview (Year 1, 2, or 3); and by whether the interview occurred near the beginning (Fall) or near the end (Spring) of the academic year.

Table 1.

Major Experiential Themes and Subthemes Identified by Study Participants

\begin{tabular}{lll}
\hline $\begin{array}{l}\text { Theme I } \\
\begin{array}{l}\text { Power dynamics: shaping and } \\
\text { being shaped }\end{array}\end{array}$ & $\begin{array}{l}\text { Theme II } \\
\text { Navigating change without a } \\
\text { road map }\end{array}$ & $\begin{array}{l}\text { Theme III } \\
\text { Evolving identities: internal } \\
\text { and external }\end{array}$ \\
\hline Subthemes & & \\
\hline $\begin{array}{l}\text { Existing and emerging cul- } \\
\text { ture }\end{array}$ & $\begin{array}{l}\text { Known and unknown } \\
\text { Spoken and unspoken } \\
\begin{array}{l}\text { Teaching and research/schol- } \\
\text { arship }\end{array}\end{array}$ & $\begin{array}{l}\text { Individual opportunities and } \\
\text { challenges } \\
\text { Institutional and individual } \\
\text { academic identities }\end{array}$ \\
$\begin{array}{l}\text { Community and socialization } \\
\text { Compond andiny }\end{array}$ & & \\
\hline
\end{tabular}




\section{Theme I. Power Dynamics: Shaping and Being Shaped}

Existing and emerging culture. Constant throughout the interviews were comments about the tension between the existing and the emerging cultures of the institution. Because the change is transformational, rather than incremental, constant upheaval was a fact of life during this period. A factor in this upheaval was the sheer number of new faculty being hired, which led to both renewed energy and instability. One participant explained:

Areas in the institution are growing exponentially and bringing in new faculty, like 30 new faculty or something like that, boom! That's huge.... Transformative change is what we are undergoing. ... It is everything all at once, and you have to expect that these things are going to be at play somewhere in this institution every moment of the day. (Cohort 1, Year 2, Spring)

The relatively large numbers of new faculty seemed to result in an interesting phenomenon: the disruption of the normal patterns of mentorship.

The big thing that I really see is the level to which the new people bond with each other and I think that is created by the circumstance, like partly because there are so many of us and because we are in the same boat. We are coming in and representing something to the established faculty and feeling a lot of tension around that because we are supposed to be deferential and mentored and we want to be mentored, but we come into a culture that is changing. (Cohort 1, Year 2, Spring)

We came to think about this as a kind of "baby boom" phenomenon during this phase of the institution's history. A concern raised by many participants was the worry that wisdom was being "lost" in the process. Participants often spoke about the tension created by the "existing and emerging cultures" for established faculty in these transitional circumstances. One commented, "When you have this many new people come in, the way it's always been doesn't cut it anymore because you have too much variation, and that sometimes really exhausts the people that have been there for a long time" (Cohort 2, Year 1, Fall). The participants' perception was usually that it was the new people primarily driving change-whether or not that was always the reality, given that the decisions and the mandate leading up to the transition were made years before their arrival. Many new faculty felt empowered to contribute positively to the transition; for example, one commented, "That is why I came here because, you know, I thought I can be of assistance. . . . And that is what I want: to contribute" (Cohort 2, Year 1, Spring).

Interestingly, some participants made a conscious distinction between the stress they would experience at any new position, and stress directly related to the institutional transition. One explained, "There are a lot of expectations that have come about because we are an institution in transition that just aren't accounted for in our workload. So they come out of-I think-people's personal stock of time and energy, and I am sensing that there is a lot of juggling going on" (Cohort 1, Year 3, Spring).

Teaching and research/scholarship. Many new faculty members applied to this institution because it is known for its focus on undergraduate teaching. As numerous other studies have demonstrated, new faculty spend an enormous amount of time on their teaching (Solem \& Foote, 2006), and these new faculty were no exception. They wanted 
to teach well, and worried about their ability to do so. Many said that the institution and its students have high standards when it comes to teaching, and they spoke of the importance of new faculty members focusing on teaching:

I need to look at the students first so that I am a good teacher and I am a teacher who knows my content and is giving them the right information, and I have time to actually develop that knowledge ability and skill, and that needs to be, I think the focus. (Cohort 2, Year 1, Spring)

Doing well at teaching and having high student evaluation scores are expected as requirements for tenure. Some participants found these expectations placed undue pressure on new faculty, while others worried that the historical teaching focus of the institution would change as a result of the new research and scholarship expectations. One participant said:

I know people are saying, "Oh, don't be worried," but it is going to change. I mean, I don't see how anyone can be ignorant enough to think it isn't going to change. I am really concerned about instructors being bought out for research. ... I would see myself wanting to focus more on teaching because I believe in that philosophy of us as a teaching institution. (Cohort 2, Year 1, Spring)

A significant concern and tension for participants trying to pursue research and scholarship was finding the time, energy, and support to do so. Again, this is common in the new faculty literature (Murray, 2008); however, participants often expressed frustration that the institution had new expectations around research and scholarship but did not reduce teaching loads enough. One participant exclaimed:

How are you supposed to do this? Like, this is impossible; how can you come in and teach three sections, starting from scratch, get research going, knowing in eight months you are going to be evaluated on all of those components, and you don't have any time to do research? (Cohort 2, Year 1, Fall)

At the same time, many participants said that they had come to the institution because they believed there would be an equitable balance in emphasis between teaching and scholarship, and that this was important to them. One participant explained her concern prior to applying. She asked herself, "Well, am I going to have to make a decision about teaching and research? I didn't want to have to let go of either one, so when I found out more about what was happening here, I realized it isn't the dichotomy I thought it was" (Cohort 1, Year 2, Spring).

Finally, there was a significant tension in the data about the valuing of research and scholarship. Some stated that they worried the institution would devalue those not doing research: "There is a little bit of a sense that if you are not interested in scholarly work you are not going to be around very long" (Cohort 1, Year 2, Spring). This contrasted with those participants who felt research and scholarship represented a threat to long-term faculty. One said, "And then they ... allege that if you want to do research and emphasize that, ... you are not taking teaching seriously, right? Like, that you are almost like a traitor and don't fit in" (Cohort 2, Year 2, Spring). Chetty and Lubben (2010) noted that the 
mid-career faculty in their study, who were also undergoing an institutional transition, saw teaching and research as dichotomous. The discussion around balancing teaching and scholarship was an enormous focus of the participants' responses, and while this tension exists at most institutions, it is evident that in this context, the transition from a solely teaching focus to that of both teaching and scholarship is one that these new faculty experienced very intensely.

Support and scrutiny. New faculty members' worries about how they will be assessed and their uncertainty about expectations are common in the literature (e.g., Murray, 2008). These new faculty spoke in a way that is consistent with that literature, making comments such as "I think the big thing is we don't know how [scholarship] will be assessed, and that is terrifying!" (Cohort 2, Year 1, Spring). The support they felt they were given in their department and by their chair made an important difference, and this varied from department to department on a full continuum ranging from new faculty who felt deeply supported to those who felt under threat. For example, one faculty member said, "People are incredibly welcoming, incredibly helpful. They have had all the things you might need: for instance, the logistics of setting up your own office to creating a survival manual with all kinds of information that is helpful to know" (Cohort 2, Year 1, Fall). In contrast, another participant said, "I think I have a lot of experience teaching and I clashed with a couple of people. . . . I was scolded like a kid ... and I just couldn't believe it. I couldn't believe the way I was treated" (Cohort 2, Year 1, Spring). One faculty member spoke about issues in the department around collegiality and being "pressured and bullied" for calling attention to policies that were not being adhered to (Cohort 2, Year 1, Spring). These kinds of experiences might be found within any post-secondary institution. However, in the case of the institution in transition, it was also a common experience for new faculty to find themselves quickly thrust into leadership positions, formal or informal, where they needed to provide answers that they didn't have yet, for example about the tenure and promotion system. Indeed, the processes themselves were in flux. One participant pointed out in relation to teaching and course development, "In fact there have been times when I am the most senior person [in my subdiscipline] around and this is my second year, so there has been a little bit of muddling through and figuring things out on my own this year" (Cohort 1, Year 2, Spring). Another participant took on a significant leadership role in her second year. She explained:

You are undergoing tenure-track obligations and that's an added burden while you are guiding other people through the process; you've only got one year advance on them. They are looking to me for leadership in a role and yet at the same time there is a slight hesitation there: "Is she telling us the right things? Does she have enough experience in this role to be giving us the guidance that we would expect to have?" ... I had no one to guide me in that same sense. (Cohort 1, Year 2, Spring)

Community and socialization. Because of the close-knit nature of a small, teaching-focused institution, participants often commented on the strong community and the opportunities (and, at times, expectations) for socializing. One participant described the welcome she received and the numerous invitations and events she had been invited to, or people stopping by her office to encourage her to attend the regular Friday gathering in the faculty centre (Cohort 3, Year 1, Fall). Perhaps because of the size of the cohorts (48 
to 59) in a relatively small institution, participants seemed to have a sense of peer support. This observation agrees with Murray's (2008) finding regarding the importance of having peers at the same stage available to new faculty, as long as those relationships are relatively harmonious.

There was a strong sense in the interviews that participants were aware of the need to adapt to the culture of the institution and the culture of their department, and to be seen as participating in the social life of both. One participant commented:

In my department there is a heavy, heavy emphasis on socialization, you are really not going to get tenure if you don't hang out with your fellow [colleagues]. I don't have a problem with that . . . but I can't do all the events. I can't even probably do half of the events that get organized and I always wonder every time I say, "Sorry I won't be there," is this the meeting I should have been at? Is this the social event I should have gone to? (Cohort 1, Year 2, Spring)

Many participants wondered aloud how important attendance at these events really was, especially when they had family obligations pulling them in another direction, and they worried about whether their regular participation was critical for tenure.

Other participants commented on the strength of the collegiality at the institution: "The community element is stronger than the competitive one" (Cohort 1, Year 3, Spring). There was speculation about how the transition to university might alter the culture of the institution; however, this is difficult to determine in the midst of change.

\section{Theme II. Navigating Change without a Roadmap}

Known and unknown. There was a great deal of discussion throughout the interviews of the tension between what was known and what was unknown. While in the literature new faculty often refer to what is "unknown" to them in the beginning (Murray, 2008), in our study the "unknowing-ness" seemed to encompass what was unknown broadly in the institution, rather than concrete things that they simply hadn't found out about yet. This was especially evident in expectations for tenure, and understandably so, since rank was introduced in the second year of this study. The criteria for achieving promotion and tenure were being developed in the third year. The expectations for research and scholarship were particularly fuzzy, and the following was a common sentiment:

I could definitely tell that I came into a time of transition and there were a lot of situations-particularly around research, where people didn't really know what the resources were, or what the expectations were, or what the tenure process was going to be, so there was definitely a lot of uncertainty. (Cohort 3, Year 1, Spring)

Spoken and unspoken. A related dynamic and tension is the contrast between what is spoken and unspoken. Many participants relayed experiences where they needed to "read between the lines" of what was said to determine the real message. This recalls Goffman's (1959) notion of the "front-of-stage aspects of culture, the public arena, backstage, where the deals are done, and under-the-stage, where gossip is shared and opinions form" (cited in Trowler \& Knight, 2000, p. 29). One participant commented, "It is about reading your culture. Reading the culture that you are in and having some kind of insight 
and savvy about yourself to be able to know some of those things that are inherent ... and not so obvious .... and not talked about" (Cohort 2, Year 1, Fall).

\section{Theme III. Evolving Identities: Internal and External}

Individual opportunities and challenges. Because of the impact of transition, in combination with the proportion of full-time faculty who were also new faculty (more than 50\%), new faculty often found themselves with leadership opportunities and heavy service loads very quickly. One participant spoke about the sheer variety of opportunity:

It's like being invited to the world's most extravagant buffet and there are all of these opportunities and it is hard to ... make the distinction of "Okay, this is what you really really need to do, versus something that might be nice down the road" (Cohort 2, Year 1, Fall).

The tension here is between opportunities and challenges-and risk. One participant talked about "the opportunities for terrible things to go wrong for a non-tenured individual to be acting in this capacity" (Cohort 1, Year 3, Spring). She was speaking of her early leadership role, but there were multiple other examples among these cohorts of surprisingly early key responsibilities. In contrast, participants also spoke about the kinds of opportunities for exploration given that the pressure for research and scholarship might be less than at other institutions:

There are things that I wouldn't necessarily do at a bigger institution-where thinking about the impact factors of journals, which ultimately influence your grants and funding, really matters-so there could be a trade-off there where you could actually do things or explore things that aren't mainstream. (Cohort 2, Year 1, Fall)

In addition, participants recognized the possibilities for growth in undertaking challenging roles at an early stage: "Am I ready? But I recognize how quickly I am growing because of that opportunity.... The experience of doing that job has pushed me miles ahead of where I would have been otherwise" (Cohort 1, Year 3, Spring).

Institutional and individual academic identities. Participants often spoke about the unique elements and reputation of the institution, as something they hoped would be preserved at the same time as it moved into the university realm. One participant expressed this tension well:

I actually think the culture has to change. I think we have to move from a college mentality to a university mentality if we want this to work. And I think ... because we have always had a different kind of relationship with our students-and I don't think that should change because that is our niche-but I think our expectations have to change. (Cohort 2, Year 1, Spring)

Other participants spoke of the differences between their perception of the institution prior to arriving, and what it turned out to be. One participant had expected there would be no ranking system initially: "I thought it was a good, socialist place" (Cohort 2, Year 1, Fall). Another commented on the community element: "People are noticeably more friendly and wanting you to socialize. ... I thought, 'Sure, this what you are telling me when I am in my interview' ... but no, it's true” (Cohort 3, Year 1, Fall). 
Thoughts about emerging and evolving (and sometimes conflicting) professional identities were present throughout the interviews. While evolving identities would be an essential component of any new faculty experience, there is a dynamic created in these data between the evolving identity of the participants against the backdrop of an institution that is moving through a transformation of identity, and the institution's effort to preserve what is most valued and core to its historical identity.

\section{Implications}

We have demonstrated through this research the impact that the transition from college to university has on the induction experience of an institution's new faculty. In addition to the typical stresses found in previous research, we found significant tensions in relation to the existing and emerging cultures, what is known and unknown, and individual opportunities and challenges. Institutions need to recognize and plan for the early experiences of new faculty, and not proceed "as usual" in relation to new faculty during periods of drastic change. If negative experiences early in the career of an academic have a lasting effect, as Boice (1991) suggests, institutions have a responsibility to new faculty, who are especially vulnerable. The exacerbation of expected and already significant stresses in the first years of a new academic position through institutional transition is, as our study shows, something to be expected, so it can be planned for. New faculty in these circumstances have the ordinary needs for orientation, mentorship, and support. However, the guidance of a supportive chair, the opportunity to network with peers, and space and time for beginning a research program are all the more important. Some buffering of service responsibilities, given the extraordinary needs of the institution in transition, might also be appropriate.

Given the exacerbation of feelings of "unknowingness," it is also important for new faculty to become involved in the development of new processes and standards for evaluation in which they have such an important stake. Thoughtful guidance for new faculty about which service responsibilities might give them such a voice would be warranted, while some protection from time-intensive service opportunities while they find their feet in the classroom would be ideal. New faculty find it difficult to say no or to distinguish qualitatively between one service opportunity and another. Recognition that typical patterns of mentorship will be disrupted in the kind of transition described, sensitivity to the experience of long-term faculty who are going through their own transitions, and acknowledging the impact of hiring large numbers of junior faculty with different priorities in short time frames are key. The characteristics of the new faculty shifted in the transition, and the tension created surrounding research and teaching was apparent and indeed still exists at the institution.

It is important to recognize that the journey of the new faculty member is not an individual one. Instead, the data in our study demonstrate that it is a complex social process. We agree with the perspectives of Trowler and Knight (2000) when they argue, "The diversity and dynamism of a university's cultural configuration derives from the smaller units within it. These are the powerhouses of university life, places where culture is both enacted and constructed and where personal identity coalesces, is shaped and re-shaped" (p. 30). These smaller units can be departments or disciplines, but also subgroups such as a cohort of new faculty, as we have shown in this study.

Viewing the post-secondary institution as an activity system, as a community of practice, or through a socio-cultural lens, as Roxa and Martensson (2009) do, can be ex- 
tremely helpful in understanding the complicated dynamics a new faculty member will experience, rather than seeing new faculty as a collection of individuals with idiosyncratic perspectives and needs. The literature argues that the systems involved are always complex. We argue that when the system itself is in flux, the experience is all the more complex. It is important for the institutional leadership, and those working to support new faculty experience, to recognize the unique demands such a circumstance places on the new faculty member in their first few years. It is critical to note that the impact of illdefined or shifting expectations for success places enormous strain on an already vulnerable group. Considering the pace of change, providing additional supports, and including new faculty voices in decision making are all key.

An important aspect of a focused ethnography is the particularity of the context. However, many institutions in Canada and worldwide have undergone or are undergoing equally significant transitions, and we hope that this work will help to inform those responsible for and impacted by such institutional change. Our study raises many questions, and the data are rich and would benefit from further analysis. Additionally, other studies are warranted to build upon this work. For example, a future study might include broadening the context to find out whether new faculty in other transitional institutions have similar experiences, and whether the dynamics found in this study are echoed. In addition, investigation into the experience of established, long-term faculty during a transition of this magnitude would also be fruitful, because the change is equally momentous for them.

\section{References}

Austin, A. E. (2003). Creating a bridge to the future: Preparing new faculty to face changing expectations in a shifting context. The Review of Higher Education, 26(2), 119144 .

Boice, R. (1991). New faculty as teachers. Journal of Higher Education, 62(2), 150173.

Boice, R. (2000). Advice for new faculty members. Boston, MA: Allyn \& Bacon.

Chetty, R., \& Lubben, F. (2010). The scholarship of research in teacher education in a higher education institution in transition: Issues of identity. Teaching and Teacher Education, 26, 813-820.

Dennison, J. D. (2006). From community college to university: A personal commentary on the evolution of an institution. Canadian Journal of Higher Education, 36(2), 107124.

Eddy, P. L., \& Gaston-Gayles, J. L. (2008). New faculty on the block: Issues of stress and support. Journal of Human Behavior in the Social Environment, 17(1-2), 89-106.

Engestrom, Y. (1987). Learning by expanding: An activity theoretical approach to developmental research. Helsinki, Finland: Orienta-Konsultit.

Engestrom, Y. (1990). Learning, working, and imagining: Twelve studies in activity theory. Helsinki, Finland: Orienta-Konsultit.

Gale, H. (2011). The reluctant academic: Early-career academics in a teachingorientated university. International Journal for Academic Development, 16(3), 215-227. 
Gonzales, L. D. (2012). Responding to mission creep: Faculty members as cosmopolitan agents. Higher Education, 64(3), 337-353.

Gonzales, L. D. (2014). Framing faculty agency inside striving universities: An application of Bourdieu's Theory of Practice. Journal of Higher Education, 85(2), 193218.

Lave, J., \& Wenger, E. (1991). Situated learning: Legitimate peripheral participation. Cambridge, UK: Cambridge University Press.

Levin, J. S. (2003). Two British Columbia university colleges and the process of economic globalization. Canadian Journal of Higher Education, 33(1), 59-86.

Knoblauch, H. (2005). Focused ethnography. Forum: Qualitative Social Research, 6(3). Retrieved from http://www.qualitative-research.net/index.php/fqs/article/view/20/43

MacQuarrie, F. A. E., Kondra, A. Z., \& Lamertz, K. (2013). Government, coercive power and the perceived legitimacy of Canadian post-secondary institutions. Canadian Journal of Higher Education, 43(2), 149-165.

Marshall, D. (2008). Differentiation by degrees: System design and the changing undergraduate environment in Canada. Canadian Journal of Higher Education, 38(3), 1-20.

Menges, R. J. (1999a). Dilemmas of newly hired faculty. In R. J. Menges (Ed.), Faculty in new jobs: A guide to settling in, becoming established, and building institutional support (pp. 19-38). San Francisco, CA: Jossey-Bass.

Menges, R. J. (Ed.). (1999b). Faculty in new jobs: A guide to settling in, becoming established, and building institutional support. San Francisco, CA: Jossey-Bass.

Muecke, M. A. (1994). On the evaluation of ethnographies. In J. M. Morse (Ed.), Critical issues in qualitative research methods (pp. 187-209). Thousand Oaks, CA: Sage.Murray, J. P. (2008). New faculty members' perceptions of the academic work life. Journal of Human Behavior in the Social Environment, 17(1-2), 107-128.

O'Meara, K., \& Bloomgarden, A. (2011). The pursuit of prestige: The experience of institutional striving from a faculty perspective. Journal of the Professoriate, 4(1), 39-73.

Perry, R. P., Menec, V. H., \& Struthers, C. W. (1999). Feeling in control. In R. J. Menges (Ed)., Faculty in new jobs: A guide to settling in, becoming established, and building institutional support (pp. 186-215). San Francisco, CA: Jossey-Bass.

Rice, R. E., Sorcinelli, M. D., \& Austin, A. E. (2000). Heeding new voices: Academic careers for a new generation. Inquiry \#7. Working paper series. New pathways: Faculty careers and employment for the 21st century. Washington, DC: American Association for Higher Education.

Roxa, T., \& Martensson, K. (2009). Significant conversations and significant networks-exploring the backstage of the teaching arena. Studies in Higher Education, 34(5), 547-559.

Solem, M. N., \& Foote, K. E. (2006). Concerns, attitudes, and abilities of early-career geography faculty. Journal of Geography in Higher Education, 30(2), 199-234. 
Sorcinelli, M. D. (1994). Effective approaches to new faculty development. Journal of Counseling \& Development, 72(5), 474-479.

Sorcinelli, M. D. (2000). Principles of good practice: Supporting early-career faculty. Guidance for deans, department chairs, and other academic leaders. Washington, DC: American Association for Higher Education.

Sorcinelli, M. D. (2002). New conceptions of scholarship for a new generation of faculty members. New Directions for Teaching and Learning, 90, 41-48.

Trowler, P., \& Knight, P. T. (2000). Coming to know in higher education: Theorising faculty entry to new work contexts. Higher Education Research \& Development, 19(1), $27-42$.

\section{Contact information}

Michelle Yeo

Academic Development Centre

Mount Royal University

myeo@mtroyal.ca

Michelle Yeo, $\mathrm{PhD}$, is an associate professor at Mount Royal University in Calgary. She works in the Academic Development Centre as a faculty development consultant in the areas of curriculum and assessment. Her work as an educational developer has an emphasis on curriculum development, revision, and review. Michelle currently conducts research in the areas of new faculty experience, disciplinary assessment practices, and SoTL.

Deb Bennett, PhD, RSW, is the coordinator of the University Entrance Option and undergraduate studies courses at Mount Royal University in the Department of General Education. The University Entrance Option supports student learning and transition experiences, a focus that fits with Deb's teaching approaches and beliefs about teaching and learning. Deb's research interests include student mental wellness, loss and grief, the scholarship of teaching and learning, and qualitative research.

Jane Stoneman McNichol is an associate professor and chair of the Public Relations Program, Faculty of Communication Studies, at Mount Royal University and a doctoral candidate in the Faculty of Education, Simon Fraser University (Vancouver). Jane is a Nexen Scholar with the Institute for the Scholarship of Teaching and Learning at Mount Royal University. Her research interests include transformational change, financial and ethical literacy, and issues and ethics in leadership.

Cari Merkley is an associate professor, Library, at Mount Royal University, where she supports student and faculty research in the School of Nursing and Midwifery. She received her master of arts and master of information studies degrees from the University of Toronto. Her current research interests include the practice of evidence-based librarianship. 